\title{
The effect of specimen thickness on the experimental and finite element characterization of CTOD in extra deep drawn steel sheets
}

D M KULKARNI ${ }^{1}$, RAVI PRAKASH ${ }^{2}$, PRAVIN TALAN $^{1}$ and A N KUMAR ${ }^{3}$

${ }^{1}$ Mechanical Engineering Group, Educational Hardware Division, and ${ }^{2}$ Research and Consultancy Division, Birla Institute of Technology and Science, Pilani 333 031, India

${ }^{3}$ Applied Mechanics, Indian Institute of Technology, New Delhi 110 016, India

e-mail: pravintalan@bits-pilani.ac.in

MS received 11 June 2003; revised 15 April 2004

\begin{abstract}
Recent experimental results by us have indicated that the load-drop technique can serve as a valid fracture criterion for predicting elastic-plastic fracture in extra deep drawn (EDD) steel sheets or in predominantly plane stress conditions. The purpose of this investigation is to examine the validity of a $J$-integral as a fracture parameter and the $J$-CTOD relation for the determination of critical CTOD in predominantly plane stress fracture (CTOD-crack tip opening displacement). Fracture tests were performed and experimental results were generated on fracture behaviour of EDD $(0.06 \% \mathrm{C})$ steel sheets with CT specimens and using 'load-drop' as a fracture criterion. Critical CTOD was determined by using the $J$ CTOD relation in addition to several existing techniques. A full 3-D finite element model was formulated to verify the critical load, critical CTOD and plastic-zone size. The critical CTOD was shown to increase with increasing specimen thickness and appeared to be approaching a higher limiting value. The characteristic features of predominantly plane stress fracture or general yielding fracture mechanics are summarized in conclusion.
\end{abstract}

Keywords. Extra deep drawn steel sheets; critical CTOD; $J$-integral; fracture criterion; general yielding fracture mechanics.

\section{Introduction}

Over half of the total metal production of the world ends up in sheet metal parts. Consequently the processing of sheet metals is of vital importance to a wide range of industries. Low carbon steels of up to about $0.15 \% \mathrm{C}$ are used in sheet metal applications. Some steels have been specially developed for sheet metal work of which extra deep drawn (EDD) steel sheets

A list of abbreviations and symbols is given at the end of the paper 
are the most popular. The wide applications of EDD steel sheets are well known in various industries for manufacturing car bodies, pipelines, domestic appliances such as bath tubs, sinks, washing machine and refrigerator bodies and so on.

Characterization of thin sheets is presently being done with the help of empirical methods and engineering simulation tests like the Erichsen cup test, Olsen cup test and hole expansion test. However, these tests described in Rao \& Emani (2000) and Ravi Kumar (2002) are influenced by different material variables (like yield strength, modulus of elasticity, strain hardening coefficient, plastic anisotropy factor and strain rate sensitivity index) and process variables (like punch and die geometry configurations, clearances etc.). The measure of cup depth or hole expansion in simulation tests is an empirical basis because cup depth or hole expansion brings out the relative engineering index for formability. However, these tests lack any fundamental scientific basis in such quantitative measurement. In intrinsic tests, formability limit diagrams (FLD) or formability limit curves (FLC) give the combination of major and minor principal strains at which necking occurs. However, according to Wu et al (2000), construction becomes tedious and consequently is limited in engineering applications. In the above-mentioned tests, in general, an attempt is made to search for an engineering parameter that indicates the mechanical environment for crack initiation and/or propagation under the corresponding experimental conditions for each of these tests. Crack initiation and propagation are commonly dealt with using fracture mechanics principles but, so far, little attention has been paid in this direction.

\section{Background}

A material for a given application is selected such that it has the required adequate toughness. In certain design problems (e.g., components of airplanes, rockets and spaceships), using plane strain fracture toughness as material property may be too conservative because structural materials are mostly used in plane stress. Adopting a very conservative approach is against the philosophy of engineering profession. Engineers always strive to obtain numbers close to reality. In aerospace applications, where the factor of safety is of the order of 1.1 for many components, using the material toughness property of plane strain is likely to make the machine heavy with poor payload. In such a situation, stress intensity factor is determined by preparing test-specimens of the same thickness as of the sheets used in the actual application. On the other hand, in the predominantly plane stress region, if the toughness value goes below the lower limit (plane strain) value, the design is made to fail.

The basic principle for obtaining fracture criteria of thin and tough sheets/plates according to Liu and his co-workers (Liu \& Ke 1976; Liu \& Kuo 1978; Liu 1981) is related to examinations of a strip necking zone, which remains embedded inside the plastic zone ahead of a crack tip in a deformed specimen. The salient conclusions of Liu's (1981) reports indicate that near tip strain or crack tip contraction can be used as a fracture criterion. The replica technique was used for the detection of crack tip necking and Moire fringe technique was used for the detection of crack tip opening displacement (CTOD). However, these techniques could not become popular, as they are too elaborate in nature for employment in quality control of sheet metals in terms of fracture mechanics-based criteria. In addition, these investigations have not indicated any rationale for detecting the physical event of crack initiation.

Kulkarni \& Ravi Prakash (2001) have reported the physical event of crack initiation using load-drop in load-line displacement plot. Critical CTOD is used as a fracture parameter. In the second paper (Kulkarni et al 2002), a 3D-FE model is proposed to verify the fracture 
behaviour. However, experimental load is used to determine the critical CTOD in the FE model. In order to check the thickness effect, the 3D-FE model should be independent of experimental values. In the present work, an attempt has been made to make the FE model independent of experimental results. Virtual crack tip opening method is used to determine critical limits of fracture parameters. In addition to this, the $J$-integral is also proposed as a second parameter to characterize fracture behaviour in EDD steel sheets. The $J$-CTOD relation is also verified in predominantly plane stress region using Shih factor, $d_{n}$ equal to one.

\section{Objectives}

There are however situations when one-parameter characterization of the crack-tip conditions fails. This is the case of large-scale yielding (or general yielding) fracture mechanics. The zone of large-scale yielding is so significant that it cannot be uniquely described by a onefracture parameter. The objectives of this present investigation are: (i) to determine the $J$ integral as a valid fracture measure using the load-drop technique, (ii) to verify the $J$-CTOD relation in predominantly plane stress fracture, (iii) to examine the effect of the variation of thickness of EDD steel sheets on their fracture criteria and (iv) verification of these results by an independent 3-D finite element model.

\section{Experimental procedure}

The experimental procedure involved the testing of EDD steel sheets using compact tension (CT) type specimens. Various tests were conducted and the results summarized.

\subsection{Specimen preparation}

The geometry of the CT specimens used in the current work followed the recommended design in ASTM (1991). Specimens were fabricated by wire electric discharge machine to maintain the exact relationship between all the dimensions. The configuration of the test specimen is shown in figure 1 . All specimens in the current study were fabricated in the $L-T$ orientation. The specimens were ground with emery papers following 1/0 (coarse), 2/0, 3/0, 4/0 (fine). These were then polished first using alundum and finally using $0.25 \mu \mathrm{m}$ diamond paste. A set of anti-buckling guide plates were designed and fabricated to avoid out-of-plane buckling during testing. Four categories of specimens with thickness 1.18, 1.38, 1.64 and $1.69 \mathrm{~mm}$ were tested.


Figure 1. Geometry of the test specimens used in fracture test as per ASTM (1991). ( $W=24 \mathrm{~mm}, B=$ thickness, $N=0.8 \mathrm{~mm}$, and $a=$ initial crack length). 


\subsection{Metallographic and mechanical test}

The composition of the investigated steel was $\mathrm{C}-0 \cdot 06, \mathrm{Mn}-0 \cdot 38, \mathrm{~S}-0 \cdot 03, \mathrm{P}-0 \cdot 017, \mathrm{Si}-$ $0.05, \mathrm{Fe}-$ the balance, all in weight $\%$, obtained from the Scientific Services Division, Tata Iron Steel Co. Ltd. The microstructure of the material revealed ferrite plus pearlite $(\sim 5 \%)$, and the average ferrite grain size was found to be $7.2 \mu \mathrm{m}$. The average tensile properties of the material were as follows: yield strength $\left(S_{Y}\right)=335 \mathrm{MPa}$, ultimate tensile strength $=387 \mathrm{MPa}$ and modulus of elasticity $(E)=210 \mathrm{GPa}$.

\subsection{Fracture test and fracture criteria}

The fracture tests were carried out using an Instron (Model 4204) Universal Testing Machine with a loading rate corresponding to the constant crack head displacement of $0.2 \mathrm{~mm} / \mathrm{min}$ at room temperature $(300 \mathrm{~K})$. Lubricated shims were used on both sides of the specimens of various thicknesses to ensure in-plane loading. During such tests, the magnitude of load $(P)$ and load line displacement $\left(V_{l l}\right)$ were recorded together with time. The load-drop technique (Kulkarni et al 2002; Kulkarni \& Ravi Prakash 2003) was used to measure related fracture parameters. The load continuously increases till a $P_{c}$ value, however, the rate of increment of load just before the critical load is very low as compared to the earlier portion of the plot. The rate of increment of load continues to decrease and as soon as the surface crack initiates, the load-drops.

The detailed dimensions of the specimens together with the critical loads obtained $\left(P_{c}\right)$ during their fracture tests are given in table 1 . The event of crack initiation is shown in a micrograph (figure 2).

\subsection{Post fracture tests}

The specimens were taken out at the event of crack initiation for subsequent measurement of CTOD and $J$ integral. The image of notch profile and grain structure was taken before the test and at crack initiation using a digital image camera attached to the electron microscope.

\section{Determination of $J$-integral}

ASTM (1987) outlines a test method for estimating the critical value of $J$ near initiation of ductile crack growth. For estimation purposes (ASTM 1987), $J_{c}$ is divided into elastic and plastic components as below:

$$
J_{c}=J_{e l}+J_{p l} .
$$

Table 1. Dimensions of the tested specimens and the critical load $\left(P_{c}\right)$ attained during fracture tests.

\begin{tabular}{cccc}
\hline $\begin{array}{c}\text { Specimen } \\
\text { code }\end{array}$ & $\begin{array}{c}\text { Thickness } \\
B(\mathrm{~mm})\end{array}$ & $\begin{array}{c}\text { Crack length } \\
a(\mathrm{~mm})\end{array}$ & $\begin{array}{c}\text { Critical load } \\
P_{c}(\mathrm{kN})\end{array}$ \\
\hline S1 & 1.18 & $10 \cdot 5$ & 1.194 \\
S2 & 1.38 & 10.5 & 1.431 \\
S3 & 1.64 & 10.5 & 1.773 \\
S4 & 1.69 & 10.5 & 1.855 \\
\hline
\end{tabular}




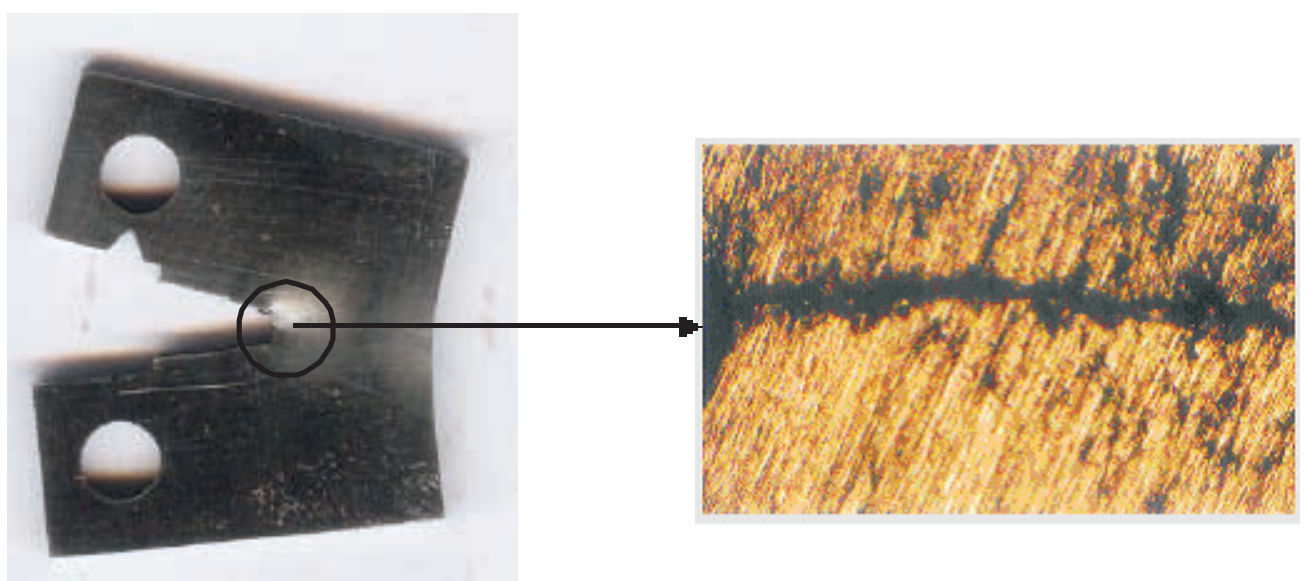

Figure 2. A micrograph (100X) showing the event of crack initiation in S1 at critical load value.

The elastic $J$ is computed from the elastic stress intensity factor by

$$
J_{e l}=K^{2} / E
$$

where, $K$, the linear stress intensity factor of the CT specimens can be derived from Srawley's equation (1975), as

$$
K=\left[P / B W^{1 / 2}\right] f(\alpha)
$$

where, $P=\left(P_{c}\right)$ load at crack initiation, $B$ is the thickness of specimen, $W$ is width of specimen and

$$
f(\alpha)=\frac{(2+\alpha)\left(0 \cdot 886+4 \cdot 64 \alpha-13 \cdot 32 \alpha^{2}+14 \cdot 72 \alpha^{3}-5 \cdot 6 \alpha^{4}\right)}{(1-\alpha)^{3 / 2}}
$$

where, $\alpha=a_{0} / W$.

ASTM (1987) enables the plastic $J$ to be estimated from the plastic area $\left(A_{p l}\right)$ under the load-load-line displacement curve (figure 3 ) as $J$ is defined in terms of the energy absorbed divided by the net cross-sectional area (thickness $(B) \times$ uncracked ligament $(b)$ ).

$$
J_{p l}=\eta A_{p l} / B b .
$$

The $\eta$ polynomial curve fit for the CT specimen is given by Panontin (2000) as

$$
\eta=41 \cdot 226(\alpha)^{3}-78.988(\alpha)^{2}+49.737(\alpha)-7.999 .
$$

\section{Estimation of critical CTOD}

Wells (1963), discovered that test samples which were too tough to be characterized by LEFM had a blunting of the crack tip. The degree of blunting increased in proportion to the toughness and was thus proposed as a fracture toughness measure. 


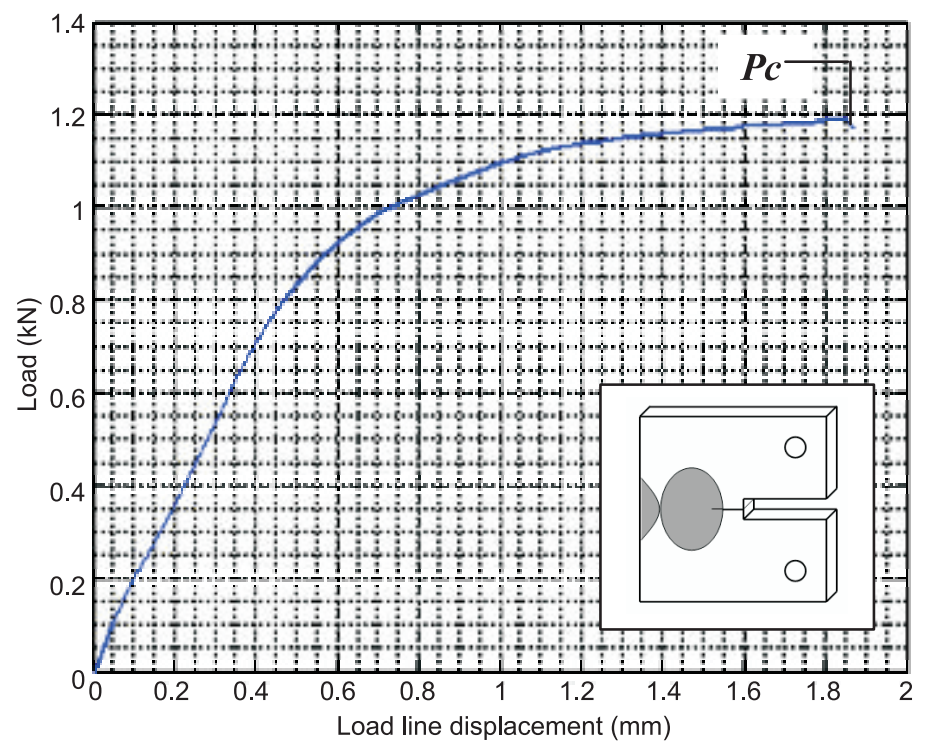

Figure 3. Load-load-line displacement plot for S1 specimen.

Following ASTM (1989), the critical crack-tip opening displacement, (5), during the loading consists of elastic and plastic parts:

$$
\begin{aligned}
\text { critical CTOD } & =\text { elastic CTOD + plastic CTOD, } \\
\delta_{c} & =\delta_{e l}+\delta_{p l} .
\end{aligned}
$$

In EDD steel sheets because of extensive plasticity, the CTOD is measured at the tip of the crack.

6.1a Calculation for the elastic part $\left(\delta_{e l}\right)$ : The elastic part was calculated by a standard method as below.

$$
\delta_{e l}=K^{2} / E S_{y},
$$

where elastic modulus $(E)$, Poisson's ratio $(v)$ and yield strength $\left(S_{y}\right)$ are the mechanical properties. $K$ was derived using (3).

6.1b Calculation for the plastic part $\left(\delta_{p l}\right)$ : Crack initiation in itself is strongly a local phenomenon. It seems reasonable to assume that the crack initiation of a ductile material is based solely on the plastic deformation behaviour (degree of blunting) near the crack tip.

(i) Plastic hinge model (PHM) - The plastic portion of $\mathrm{CTOD}_{c}\left(\delta_{p l}\right)$ is determined (Kumar (1991, 1995) by assuming that the uncracked ligament works like a plastic hinge with its centre at a distance $r_{p l} b$ from the crack tip as shown in figure $4 \mathrm{a}$. Referring to figures $4 \mathrm{a}$ and $\mathrm{b}, \mathrm{O}$ is the apparent axis of rotation, $\mathrm{G}$ is crack tip, $A B$ is the plastic part of the CTOD $\left(\delta_{p l}\right)$, $C D$ is plastic load line displacement $\left(=V_{p l}\right)$, and $G H\left(=a_{0}\right)$ is initial crack length. $O G$ is 


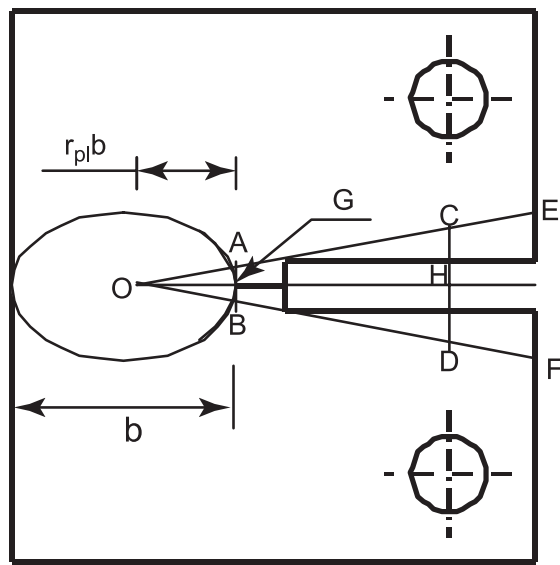

(a)

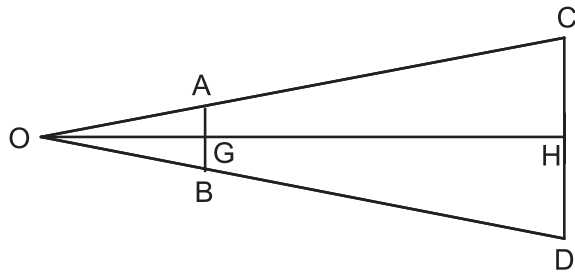

(b)

Figure 4. (a) Plastic hinge model (PHM) and (b) geometry of crack tip opening displacement (AB) and load-line displacement $(\mathrm{CD})$ at crack initiation.

taken equal to $r_{p l} b$, where $r_{p l}$ is a plastic rotational factor and $b$ is the ligament length. From properties of the similarity of triangles (figure $4 b$ ),

$$
\begin{aligned}
\frac{A B}{C D} & =\frac{O G}{O G+G H} \text { or } \frac{\delta_{p l}}{V_{p l}}=\frac{r_{p l} b}{r_{p l} b+a_{0}}, \\
\delta_{p l} & =\frac{r_{p l} b}{r_{p l} b+a} V_{p l} .
\end{aligned}
$$

Equation (7) is based on the 'plastic hinge model' (PHM), where the two halves of the specimen rotate about an apparent axis of rotation passing through point ' $\mathrm{O}$ ' and perpendicular to the plane of the specimen. According to Merkle \& Corten (1974) the value of plastic rotational factor $\left(r_{p l}\right)$ is based on fully plastic limit solution and is found to be $(1+\alpha) / 2$, where,

$$
\alpha=\left[\left(2 a_{0} / b\right)^{2}+\left(4 a_{0} / b\right)+2\right]^{1 / 2}-\left[\left(2 a_{0} / b+1\right] .\right.
$$

The value for $V_{p l}$ was taken from the load-load-line displacement plot (figure 3). Using (5)(7), the values of critical CTOD $\left(\delta_{c}\right)$ were calculated for different thicknesses.

(ii) Optical microscopy $(O M)$ - Using graduated lens in an optical microscope, the plastic part of CTOD could be measured. First, a horizontal distance of $3 \mathrm{~mm}$ is traveled to reach an original crack-tip point and then, at this point, vertical distance is measured as a plastic CTOD shown in figure 5.

(iii) $90^{\circ}$ intercepts $\left(90^{\circ}\right)$ - The $90^{\circ}$ intercept definition of CTOD was suggested by Rice (1968). Figure 6b shows the image of a notch profile before the test. Two mutually perpendicular lines at (current notch tip) point $\mathrm{O}^{\prime}$ were drawn on an image of notch profile after the test. The displacement between two $90^{\circ}$ lines at the intersection with the crack flanks was inferred as a plastic CTOD shown in figure $6 \mathrm{a}$. 




Figure 5. (CTOD) $)_{p l}$ measurement by optical microscopy (OM).

(iv) Using the $J$-CTOD relation $(J)$ - The plastic CTOD, $\left(\delta_{p l}\right)$, can be derived from the value of $J_{p l}$, using the well-known relationship:

$$
(C T O C D)_{p l}=d_{n}\left(J_{p l} / S_{y}\right)
$$

where $d_{n}$, is a factor tabulated by Shih (1981). The factor $d_{n}$ is shown in the range of 0.40.8 for plane strain condition. In large-scale or general yielding, this value is taken as 1 for structural steels in predominantly plane-stress conditions.

The amount of contraction (crack tip necking) was measured by using a pointer micrometer at a deep point in the vicinity of the crack tip.

\section{Determination of plastic zone size and shape}

A designer trying to avoid fracture of a component prefers to have a large plastic zone at the crack-tip. This is contrary to the preference of a conventional designer, who tries hard to avoid yield at any portion of a component.



(a)

(b)

Figure 6. Determination of $(\mathrm{CTOD})_{p l}$ from a micrograph $(40 \mathrm{X})$ by using $90^{\circ}$ intercept. (a) Notch profile after fracture test and (b) notch profile before fracture test. 
The plastic zone plays a vital role in fracture mechanics. If one moves on a radial line from a far away place (where the stress field is definitely elastic) towards the crack-tip and a yield criterion is being continuously applied, then as soon as the material is found to yield, the point can be marked as the interference between the elastic and plastic fields.

(i) Analytical - To ensure yielding of material, the Von Mises criterion states that

$$
\left(\sigma_{1}-\sigma_{2}\right)^{2}+\left(\sigma_{2}-\sigma_{3}\right)^{2}+\left(\sigma_{3}-\sigma_{1}\right)^{2} \geqslant 2 S_{y}^{2} .
$$

The radius of the plastic zone is derived as

$$
r_{p z}=(1 / 4 \pi)\left(K_{I} / S_{y}^{2}\right)\left(1+\frac{3}{2} \sin ^{2} \theta+\cos \theta\right) .
$$

The size is estimated using (9) and plotted as shown in figure 7.

(ii) Optical microscopy - Using graduated lens (10X) in an optical microscope, the plastic zone can be easily measured. The magnified image clearly differentiates between yield surface and yield surface. Following the interface boundaries and picking some key points, the plastic zone size and shape are determined.

(iii) Hardness measurement - The plastic zone size and shape is also predicted by measuring hardness along and across the unbroken ligament figure $8 \mathrm{~b}$. The hardness is measured by using a micro-hardness tester (Shimadzu HMV). The hardness (HV) values and variations at specific points are shown in figure 8 .

\section{Computational approach}

The computational approach involves detailed finite element analysis of the experimental results. Thus it is possible to determine the stress and plastic strain fields in the vicinity of the crack front and their evaluation with loading.

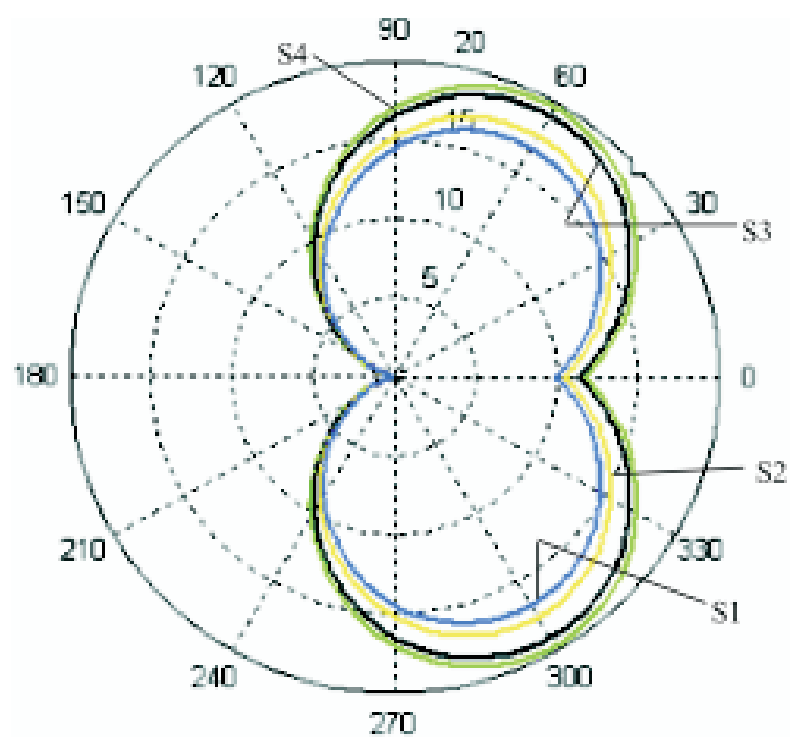

Figure 7. Plastic zone size estimation by using Von Mises criterion. 

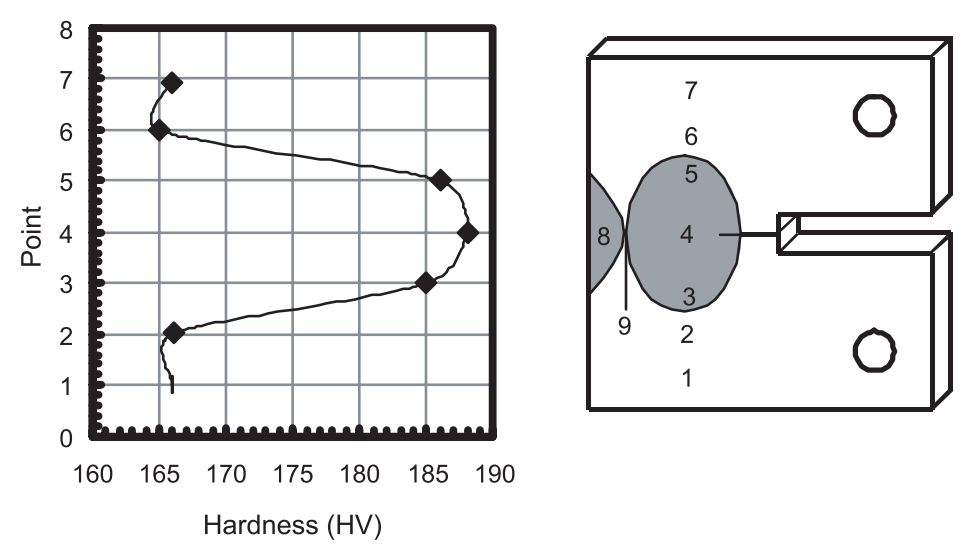

Figure 8. Hardness measurement along (a) and across (b) the unbroken ligament.

\subsection{3-D Finite element analysis}

The 3-dimensional geometry of a CT specimen was modelled similar to the ASTM standard (ASTM 1991) (as shown in figure 1). However, for mode I type modelling, by exploiting the geometry, loading, material and support symmetry conditions, two planes of symmetry were considered: one at mid-height and other at mid-thickness of the test specimen. The brick element was defined by using 20 nodes having 3 degrees of freedom per node and translations in $x$-, $y$ - and $z$-directions.

Meshing was graded from fine at the crack tip to coarse at the solid boundary. The most important region in a fracture model is the region around the edge of the crack. The element size that ranges from $0.035 \%$ to $0.060 \%$ of the absolute crack length was considered around the crack tip. A triangular wedge-shaped element was formed by collapsing the top plane of a brick element along the surface diagonal. The elements with multiple nodes are arranged along different radial lines around the crack tip. These elements are quadratic in behaviour. The mid-side nodes of the elements in the first radial line are placed at the quarter positions to produce the appropriate $1 / r$ singularity as the limit of the plasticity is approached. This element is referred as a singular element, which was derived by Blackburn (1976). These elements are capable of sustaining the anticipated large strain as mentioned in the report of Degiorgi \& Matic (1990).

In finite element model, fine mesh is adopted at pin-holes to prevent local effects of nodal displacement. The coincident nodes in the wedge-shaped elements at the crack front were left unconstrained to allow appropriate development of crack tip blunting. This is referred as 'virtual crack tip opening method'.

\subsection{Linear analysis}

The value of stress intensity factor needed to calculate elastic CTOD was found using:

$$
K_{I}=\sigma_{i j}\left(\sqrt{2 \pi r} / g_{i j}^{I}(\theta)\right),
$$

where, $g_{i j}^{I}(\theta)$ is function of $\theta$ and $\sigma_{i j}$ is the stress value of the node having maximum displacement at radius $r$, and an angle $\theta$ with the crack plane. Now using (6), the elastic CTOD is determined. 


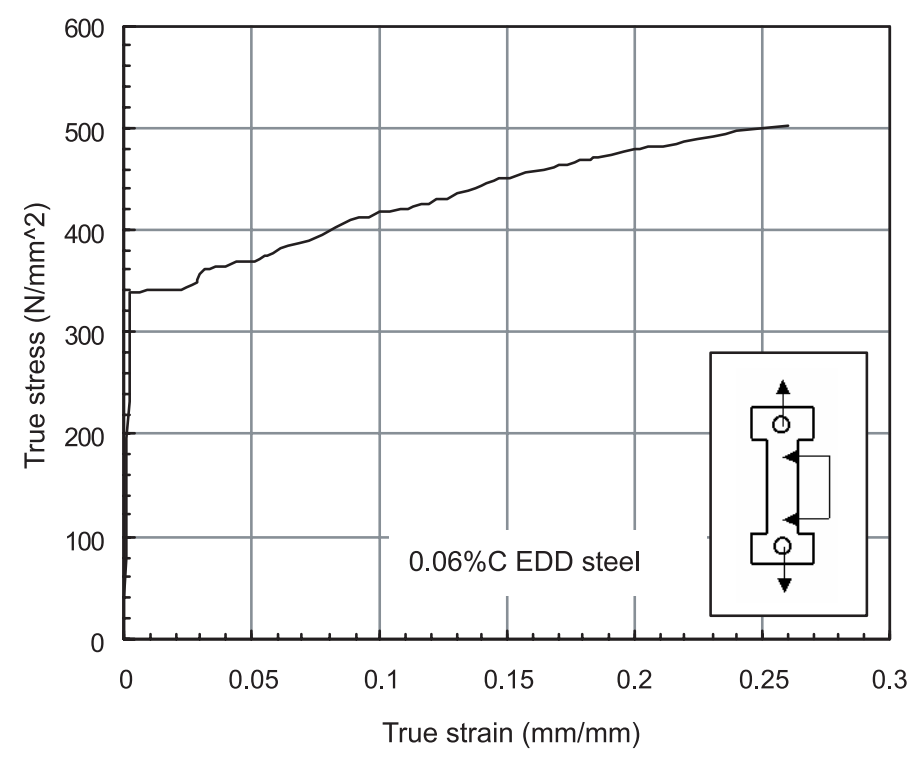

Figure 9. True stress-logarithmic strain curve for EDD steel sheet.

\subsection{Nonlinear analysis}

Elastic-plastic finite element analysis can be considered as an extension of those for the elastic by incorporating extra conditions pertaining to nonlinear plasticity conditions due to Newman (1984). Nonlinear material behaviour was modelled by using the incremental theory of plasticity. Von Mises yield criterion was considered to be valid for these materials. Large strain code with multi-linear isotropic hardening was used to model material nonlinearity and to estimate critical load value.

The true stress-logarithmic strain curve of the material is shown in figure 9. The elasticplastic process requires a continuous assessment of stress and plastic strain at all points of the structure, as the load-line displacement increases. Hence the displacement is applied in sequence of relatively small time steps to maintain the experimental load-line displacement rate. Within each time step, check on stress and equilibrium is made. As load-line displacement starts, the program starts to iterate the stress above the yield stress to consider the plastic effects. The whole nonlinear curve is considered to consist of a number of straight lines. With the help of this analysis, the values of plastic CTOD $\left(\delta_{p l}\right)$ and crack tip necking $\left(\delta_{n}\right)$ are determined at the same node considered in linear analysis. The results of plastic CTOD and crack tip necking are shown in figures 10a and b respectively, for an S1 specimen.

\section{Discussion}

In this investigation, two distinct deviations from the work of Liu and his co-workers were considered for computing fracture criteria of thin sheets. First, since crack initiation can be physically determined with the load-drop phenomenon, fracture criterion is considered to correspond to the value of critical load $P_{c}$ and critical CTOD $\left(\delta_{c}\right)$. Second, since for thin sheets the magnitude of CTOD is high enough, an obvious simplification leads to the elimination 

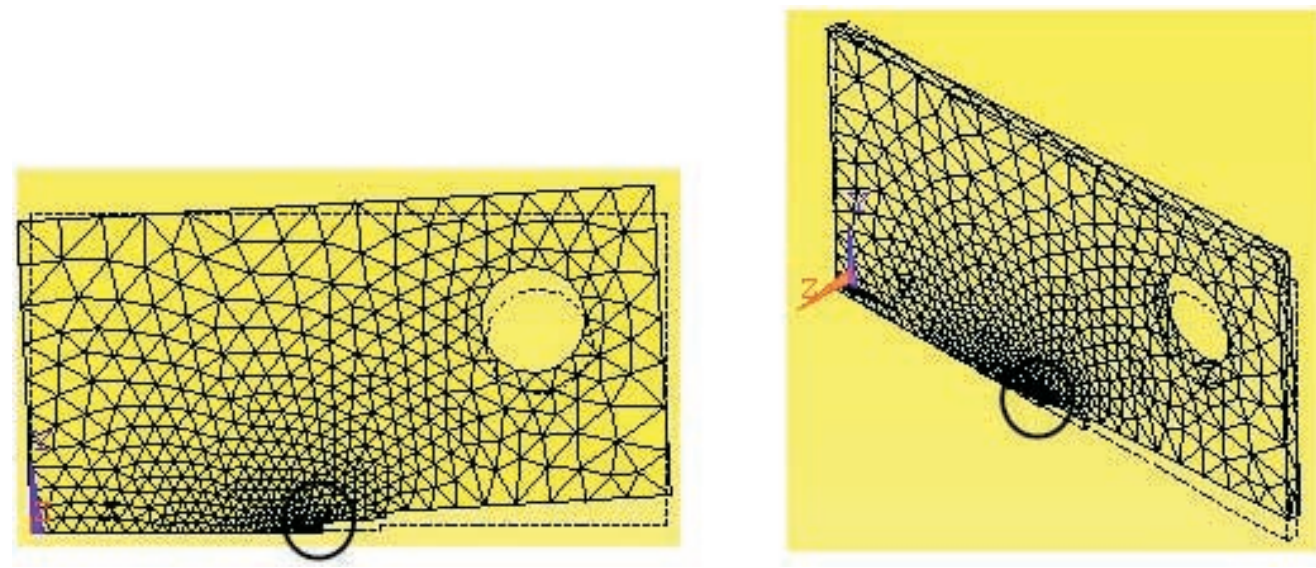

Figure 10. FEM results on (a) crack-tip opening displacement, (b) crack-tip necking.

of the plastic part of CTOD $\left(\delta_{p l}\right)$ measurements by the Moire fringe technique or estimation of crack tip necking $(\delta n)$ by the replica technique because CTOD $c$ can be simply estimated with the help of optical microscope, plastic hinge model, and $90^{\circ}$ intercept. This estimation is also supported by $J$-CTOD relation.

The area under the load-load-line displacement is used to determine the plastic part of $(\mathrm{CTOD})_{c}$ and $J_{c}$. Figure 11 shows the variation of $J_{c}$ with specimen thickness in the plane stress dominated zone. The $J$-CTOD relation is found to be validated as the CTOD results are found in good agreement with $\mathrm{OM}, 90^{\circ}, \mathrm{PHM}$ and FE results as shown in figure 12 . The plastic zone size $\left(r_{p z}\right)$, predicted by analytical, experimental and FE predictions are within $22 \%$. The total plastic zone across the unbroken ligament figure $8 \mathrm{~b}$ consists of tensile zone around the crack-tip and compressive zone towards the ligament boundary as shown in figure 13 . The apparent axis of rotation or a neutral point (figure 14) between these two zones is at a distance of $8.02 \mathrm{~mm}$ estimated by Merkle \& Corten (1974), $7.5 \mathrm{~mm}$ measured by OM and $7.62 \mathrm{~mm}$ predicted by FE analysis from the crack-tip. In FE analysis for all thickness models, there is a specific nodal position on the unbroken ligament figure $8 \mathrm{~b}$, which has a far-field

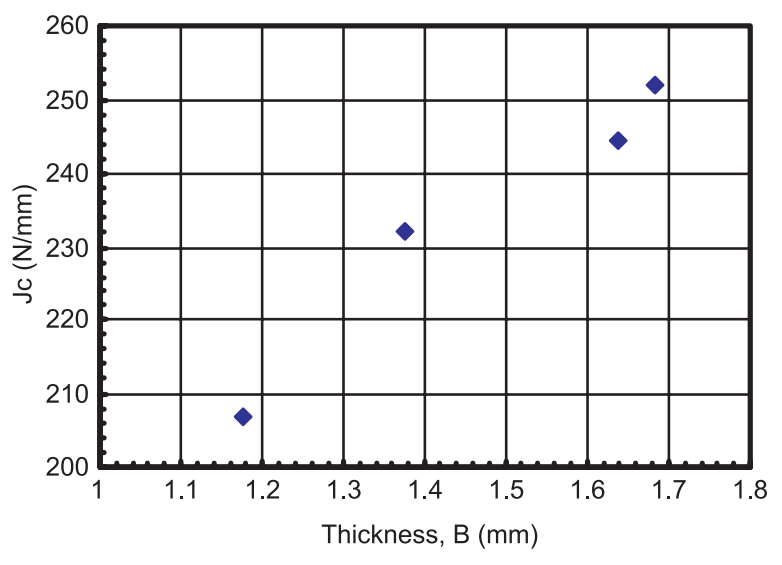

Figure 11. Variation of experimental $J_{c}$ with specimen thickness. 


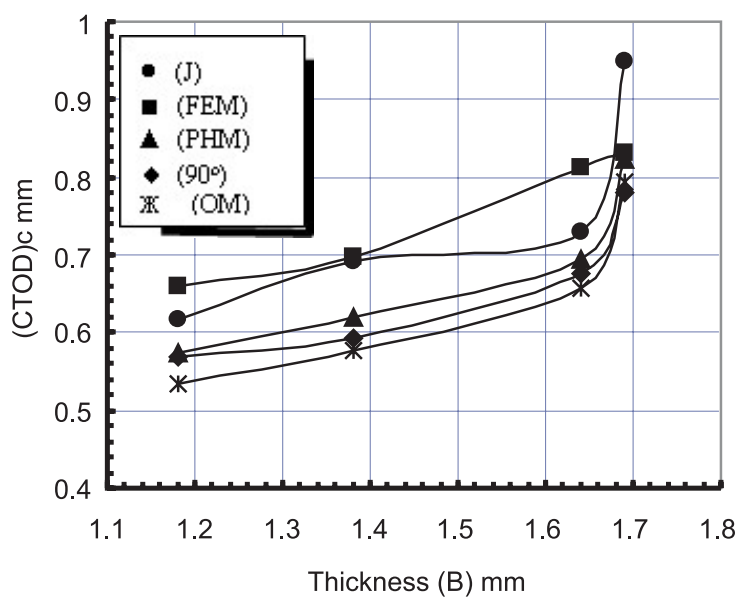

Figure 12. Variation of critical CTOD with thickness of specimen.

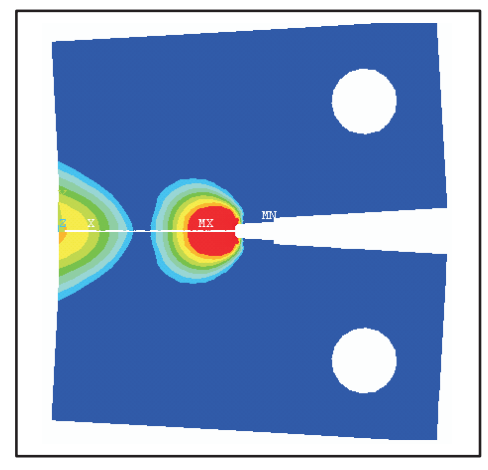

(a)

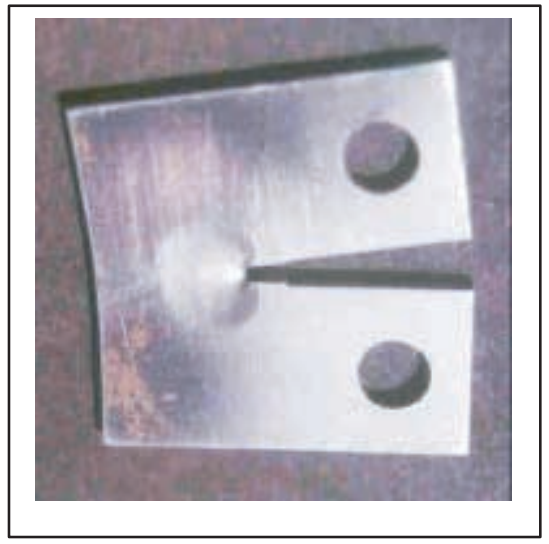

(b)

Figure 13. Plastic zone size and shape for S1: (a) FE prediction. (b) Experimental.

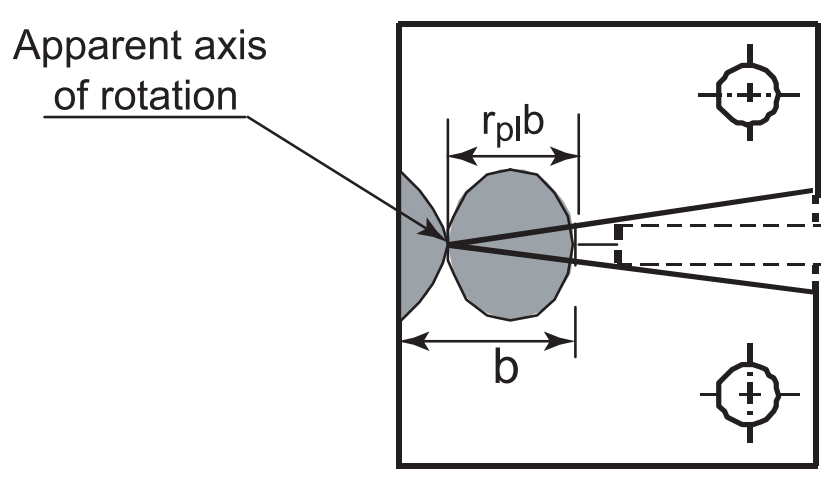

Figure 14. Apparent axis of rotation in plastic hinge model (PHM). 


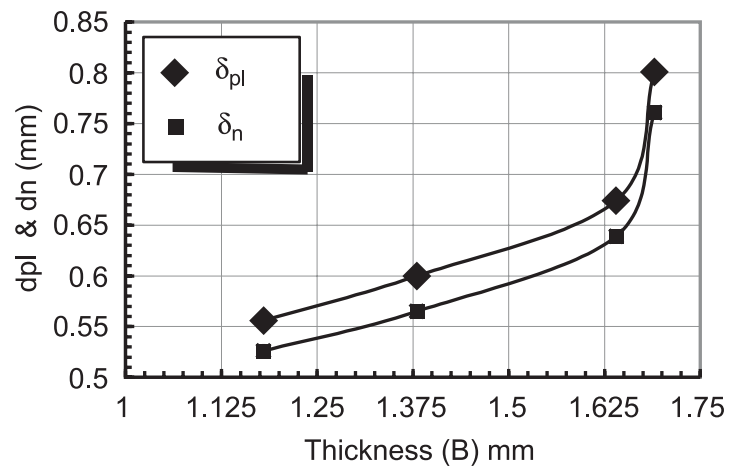

Figure 15. Variation of plastic CTOD and crack-tip necking with the thickness of specimen.

stress value. This position depends on thickness value. This is also supported by the hardness measurement as shown in figure 8. The salient conclusions of Liu's (1981) reports indicate that the near tip strain or crack tip contraction may be used as a fracture criterion with cracktip necking $\approx$ CTOD. However, figure 15 shows that the difference between CTOD and CT necking increases slowly with increase in thickness of the specimen.

Breaking strain and virtual crack tip opening method, is used in the 3-D FE model to predict the critical load value. The estimation of critical load $\left(P_{c}\right)$, critical CTOD $\left(\delta_{c}\right)$ and crack-tip necking $\left(\delta_{n}\right)$ are on the higher side and within $4-10 \%$ higher than the experimental values.

\section{Conclusions}

The results of this study show that the 'CTOD' parameter can be successfully characterized for increasing thickness of EDD $(0.06 \% \mathrm{C})$ steel sheets. The stress-strain field around the crack-tip is described with the help of two parameters: $J$ and CTOD. The methods adopted in the present paper are remarkably convenient in application. Key findings from this study are summarized as follows.

(i) The $J$-CTOD relation is validated in predominantly plane-stress region. Both the parameters describe the fracture behaviour at the crack-tip. This is a 'strain-controlled' phenomenon rather than 'stress-controlled' phenomenon.

(ii) The critical CTOD increases with increase in specimen thickness and appears to approach a higher limiting value. This is a characteristic feature of general yielding fracture mechanics.

(iii) The plastic zone in general yielding fracture mechanics (or predominantly plane stress region touches the ligament boundary of the specimen and also increases with increase in specimen thickness, unlike that for thick plates as reported by Srawley \& Brown (1975).

(iv) The apparent axis of rotation depends only on $a_{0} / W$ ratio and is independent of thickness of specimens. The location of this point could be easily predicted by FE analysis.

(v) The critical load values by FE analysis are slightly overestimated and within 4-10\% of experimental results. This discrepancy is attributed to assumed idealized conditions in the FE model. 
The authors greatly acknowledge the cooperation of Prof. J C Newman, Department of Aerospace Engineering, Mississippi State University, USA for the FE analysis and related discussions.

\section{List of symbols}

$\begin{array}{ll}a_{0} & \text { initial crack length; } \\ B & \text { thickness of specimen; } \\ \text { CTOD, (CTOD) } c & \text { crack tip opening displacement and critical crack tip opening } \\ & \text { displacement respectively; } \\ d_{n} & \text { Shih factor; } \\ E & \text { elastic modulus; } \\ J_{e l}, J_{p l}, J_{c} & \text { elastic, plastic and critical } J \text { respectively; } \\ K & \text { stress intensity factor; } \\ P_{c} & \text { critical load; } \\ r & \text { distance of node from crack tip; } \\ r_{p l} & \text { plastic rotational factor; } \\ r_{p z} & \text { plastic zone size; } \\ S_{Y} & \text { yield strength; } \\ V_{l l}, V_{e l}, V_{p l} & \text { load line displacement, elastic load line displacement and plastic load } \\ W & \text { line displacement respectively; } \\ \eta & \text { width of specimen; } \\ \delta_{e l}, \delta_{p l}, \delta_{c} & \text { polynomial curve fit; } \\ \delta_{n} & \text { elastic, plastic and critical CTOD respectively; } \\ v & \text { crack tip necking; } \\ \sigma_{i j} & \text { Poisson's ratio; } \\ \theta & \text { nodal stress value; }\end{array}$

\section{References}

ASTM 1987 American Society for Testing and Materials, E813-87, Philadelphia, PA ASTM 1989 American Society for Testing and Materials, E1290-89, Philadelphia, PA ASTM 1991 American Society for Testing and Materials, E399-91, Philadelphia, PA

Blackburn 1976 On the use of singular finite elements in linear fracture mechanics. Int. J. Numer. Methods Engng. 10: 25-37

Degiorgi V G, Matic P 1990 An experimental and computational investigation of crack growth in three-point bend fracture specimens. Engng. Fracture Mech. 37: 1039-1058

Kulkarni D M, Ravi Prakash 2001 Experimental \& finite element analysis of fracture criterion of extra deep drawn steel sheets. Proc. 10th ICF (Int. Cong. on Fracture), Hawaii, pp 432-438

Kulkarni D M, Ravi Prakash 2003 Experimental analysis of fracture criterion in general yielding fracture mechanics. J. Inst. Eng. (India), 84: 18-21

Kulkarni D M, Ravi Prakash, Kumar A N 2002 Experimental and finite element analysis of fracture criterion in general yielding fracture mechanics. Sädhanā 27: 631-642

Kumar A N 1991 A new approach for CTOD evaluation in slow crack growth situations. Engng. Fracture Mech. 40: 1089-1103

Kumar A N 1995 Modeling of rotational factor in notched bend specimen under general and local yield situation. Theor. Appl. Fracture Mech. 24: 1995 33-46 
Liu H W 1981 Fracture mechanics of ductile and tough materials and its applications to energy related structures (The Hague: Martinus Nijhoff) pp 189-198

Liu H W, Ke J S 1976 Thickness effect on crack tip deformation on fracture. Engng. Fracture Mech. 8: $425-436$

Liu H W, Kuo A S 1978 Fracture toughness of thin and tough plates. Int. J. Fracture 14: R109-R112

Merkle J G, Corten H T 1974 J. Pressure Vessel Technol. 96: 286-292

Panontin T N, Makino A, Williams J F 2000 Crack tip opening displacement estimation formulae for C(T) specimens. Eng. Fracture Mech. 67: 293-301

Newman J C Jr 1984 An elastic-plastic finite element analysis of crack initiation, stable crack growth and instability. ASTM STP 833, pp. 93-117

Rao K P, Mohan E V R 2000 Direct evaluation of sheet metal forming properties under various deformation conditions. Fracture and strength of solids (Trans. Tech. Publications - Key Engineering Materials) 177-180: 509-516

Ravi Kumar D 2002 Formability analysis of extra-deep drawing steel. J. Mater. Process. Technol. 31: $31-41$

Rice J R 1968 A path independent integral and the approximate analysis of strain concentration by notches and cracks. J. Appl. Mech. 35: 379-386

Shih C F 1981 Relationship between the $J$ integral and the crack opening displacement for stationary cracks. J. Mech. Phys. Solids. 29: 305-326

Srawley J E, Brown W F 1975 Fracture toughness testing and its applications. ASTM STP No. 381, Philadelphia, PA, 133-198

Wells A A 1963 Application of fracture mechanics at and beyond general yielding. Br. Welding J. 10: 563-570

Wu P D, Graf A, Jain M, MacEwen S R 2000 On alternative representation of forming limits. Fracture and Strength of Solids (Trans. Tech. Publications - Key Engineering Materials) 177-180: 304-309 